\title{
Farklı Renk Kompomerlerin Polimerizasyon Esnasında Direkt Işık Geçirgenliklerinin Değerlendirilmesi: Radyometrik Bir Çalışma
}

\section{Evaluation of Direct Light Transmittance of Different Color Compomers during Polymerization: A Radiometric Study}

\author{
${ }^{1}$ Bilal ÖZMEN, ${ }^{1}$ Zeynep KAYA, ${ }^{2}$ Hatice Zehra BODUR GÜNEY \\ ${ }^{1}$ Ondokuz Mayıs Üniversitesi, Diş Hekimliği Fakültesi, Pedodonti Anabilim Dalı, Samsun,Türkiye \\ ${ }^{2}$ Giresun Üniversitesi, Diş Hekimliği Fakültesi, Pedodonti Anabilim Dalı, Giresun,Türkiye
}

Bilal Özmen: https://orcid.org/0000-0002-4435-288X

Zeynep Kaya: https://orcid.org/ 0000-0003-1576-9560

Hatice Zehra Bodur Güney: https://orcid.org/ 0000-0001-7416-3177

\begin{abstract}
ÖZ
Amaç: Kompomer rezinin kalınlığ 1 ve rengi, polimerizasyonda kullanılan ışı̆̆ın iletimini etkileyebilir. $\mathrm{Bu}$ çalışmanın amacı aynı marka farklı renk tonunda kompomer rezinlerin polimerizasyonları esnasındaki direkt 1şık geçirgenliklerini değerlendirmektir.

Materyal ve Metot: Bu amaçla A2, A3, A3,5, A4, B3 ve C2 renk Glasiosite caps kompomerler (Voco, Germany) kullanıldı. Her renk grubu için silindir şeklinde $2 \mathrm{~mm}$ kalınlığında ve $8 \mathrm{~mm}$ çapında 10 örnek hazırlandı. Tek bir 1şık cihazıyla (Woodpecker Led G, China) polimerize edilen örneklerin direkt 1şı geçirgenliği dijital bir radyometre (SDI, Australia) ile 1., 5., 10., 15., ve 20. saniyelerde ölçüldü. Veriler Duncan çoklu karşılaştırma testi kullanılarak analiz edildi.

Bulgular: En az direkt 1şık geçirgenlik değeri C2 renk kompomerlerde birinci saniyede, en fazla direkt 1şı geçirgenlik değeri A2 renk kompomerlerde 20. saniyede gözlendi. A2, A3 ve B3 gruplarından elde edilen direkt 1ş1k geçirgenliği değerleri birbirine benzer olarak bulundu. Sonuç: Kalınlıkları ve üreticisi aynı olan farklı renk kompomerlerin direkt 1şı geçirgenlik değerlerinin farkl olduğu ve kompomer rezinlerde kullanılan renk pigmentlerinin direkt 1şı iletim değerlerini etkilemekte olduğu sonucuna ulaşıldı.

Anahtar Kelimeler: Işık geçirgenliği, kompomer, radyometre
\end{abstract}

\section{ABSTRACT}

Objective: The thickness and color of the compomer resin can affect the transmission of light used in polymerization. The aim of this study was to evaluate the direct light transmittance of the same brand different color tone compomer resins during polymerization.

Materials and Methods: For this purpose, A2, A3, A3,5, A4, B3 and C2 color Glasiosite caps compomers (Voco, Germany) were used. For each color group, 10 samples in the form of cylinders, $2 \mathrm{~mm}$ thick and $8 \mathrm{~mm}$ diameter were prepared. The direct light transmittance of the samples polymerized with a single light device (Woodpecker Led G, China) was measured with a digital radiometer (SDI, Australia) at the 1st, 5th, 10th, 15th and 20th seconds. Data were analyzed using Duncan multiple comparison test.

Results: The lowest direct light transmittance value was observed in $\mathrm{C} 2$ color compomers in first second, and the highest direct light transmittance value was observed in A2 color compomers in 20th seconds. Direct light transmittance values were found to be similar in A2, A3 and B3 groups.

Conclusion: Different shade compomers with the same thickness and manufacturer have different direct light transmittance values and color pigments used in compomer resins affect the direct light transmission values. Keywords: Compomer, light transmittance, radiometer
Sorumlu Yazar / Corresponding Author:

Zeynep Kaya

Ondokuz Mayıs Üniversitesi, Diş Hekimliği Fakültesi, Pedodonti Anabilim Dalı, 55139, Atakum, Samsun, Türkiye

Tel: +90 5446113039

E-mail: zeynepkaya.2508@hotmail.com
Yayın Bilgisi / Article Info:

Gönderi Tarihi/ Received: 26/10/2020

Kabul Tarihi/ Accepted: 14/01/2021

Online Yayın Tarihi/ Published: 05/03/2021

Atıf / Cited: Özmen B, ve ark. Farklı Renk Kompomerlerin Polimerizasyon Esnasında Direkt Işsk Geçirgenliklerinin Değerlendirilmesi: Radyometrik Bir Çalışma. Online Türk Sağlık Bilimleri Dergisi 2021;6(1):112-120. doi: 10.26453/otjhs.816289 


\section{GİRIŞ}

Kompomerler ya da diğer adıyla poliasit-modifiye kompozit rezinler çocuk diş hekimliğinde yaygın bir kullanım alanı bulan estetik restoratif materyallerdendir. Kompomerler 90'lı yıllarda tanıtılmış olup, kompozit rezinlerin estetik özellikleri ve cam iyonomer simanların flor salma özellikleri bir araya getirilerek üretilmiş, kompozitlerin "komp" kısmı ile cam iyonomerlerin "omer" kismı bir araya getirilerek "kompomer" olarak adlandırılmışlardır. Flor salınımı yapması, renk seçeneklerinin bulunması, estetik özelliklerinin iyi olması, polimerizasyonunun 1şı1kla sağlanması, iyi özelliklerindendir. ${ }^{1}$

Kompomerlerde ana yapı kompozitlere benzer olarak bisglycidyl ether dimethacrylate (BisGMA), urethane dimethacrylate (UDMA) ve viskoziteyi azaltmak için kullanılan triethylene glycoldimethacrylate (TEGDMA) gibi monomerlerdir. Doldurucu olarak reaksiyona girmemiş inorganik tozlar, quartz ve cam silika içerirler. ${ }^{2}$ Kompozitlere benzer olarak kompomerlerde de sertleşme reaksiyonunun başlatılabilmesi için başlatıcı olarak genellikle kamforokinon kullanılır. Kamforokinon 450-470nm dalga boyundaki mavi 1şı̆̆a duyarlıdır. Polimerizasyonun yeterli sürede ve güçte uygulanması ile kamforokinon sarı rengini yitirir ve renksiz bir hale gelir. Yeterli uygulanmayan polimerizasyon estetik materyalin sarımsı kalmasına sebep olabilir. ${ }^{3}$ Ayrica yeterli polimerizasyon uygulanmaması materyalde artık monomerlerin kalmasına sebep olur. Artık monomerler hem pulpa sağlığı hem de genel sağlık için problem oluşturabilir. Bu nedenle kullanılacak estetik restoratif materyalin özellikleri ve polimerizasyon için kullanılacak ışık cihazının özelliğinin çok iyi bilinmesi gereklidir. ${ }^{4}$

Geleneksel 1şık cihazları, 800-1000 mW/ $/ \mathrm{cm}^{2}{ }^{2}$ 1şı şiddeti ve ortalama $400-500 \mathrm{~nm}$ dalga boyundaki görünür 1şığa sahiptir. $2 \mathrm{~mm}$ kalınlığında bir rezin tabakasının polimerizasyonu için 40 sn uygulama süresi yeterlidir. Daha sonraları "1şı salan diod sistemlerin" (LED) üretilmesi ile 1şık şiddeti 1000 $\mathrm{mW} / \mathrm{cm}^{2}$ ve daha fazla olan cihazlarla polimerizasyon süresi azaltılmıştır. Ayrıca taşınabilir ve uzun ömürlü olmaları ve iyi bir polimerizasyon düzeyi sağlamaları da LED ışık kaynaklarının avantajları arasındadır ve bu cihazların klinik kullanımları giderek artmaktadır. ${ }^{5}$

Dental rezinler estetiği sağlamak adına diş rengine uygun farklı renk skalalarında üretilmektedir. En sık tercih edilen skala olan VITA skalası A; kırmızımsı kahverengi, B; kırmızımsı sarı, C; gri ve D; kırmı- zımsı gri olmak üzere 4 temel renge ayrılır. Bu renkleri elde edebilmek için kullanılan renk verici malzemeler 1şı̆̆ın materyalden geçerken saçılmaya uğramasına sebep olabilir ve polimerizasyonunu etkileyebilir. $^{6,7}$

Kullanılan materyalin kalınlığ 1 ve rengi, 1şığın geçirgenliğini belirleyen önemli etkenler arasında gösterilebilir. ${ }^{8}$ Genel olarak estetik restoratif materyallerin en fazla $2 \mathrm{~mm}$ kalınlıkta uygulanması gerektiği belirtilmektedir. Kullanılan estetik materyalin kalınlığının artmasının, materyalin 1 şık geçirgenliğini azalttığı, koyu renkli kompozitlerin opak olanlara göre daha az 1şık geçirgenliğine neden olduğu önceki çalışmalarda gösterilmiştir. ${ }^{9}$ Ayrıca polimerizasyon için kullanılan ışık cihazı gücüne, tipine, uygulama moduna, uygulama süresine, 1ş1k ucunun özelliğine, 1şık cihazının örneğe olan mesafesine, kompozit rezinin markasına ve içeriğine bağlı olarak da polimerizasyon derinliğinin değiştiği, ${ }^{10,11}$ fakat kompomerlerin daha derinlere 1 şı penetrasyonu gösterdiği bildirilmektedir. ${ }^{12}$

Koyu tonlardaki kompomer rezinlerin direkt 1 şı geçirgenliğinin açık tonlardaki kompomer rezinlere göre daha az olduğu hipotezi ile planlanan bu çalışma, aynı markaya ait farklı renk tonlarında kompomer rezinlerin polimerizasyon esnasındaki direkt ışı geçirgenliğini değerlendirmek amacı ile yapıld1.

\section{MATERYAL VE METOT}

$\mathrm{Bu}$ çalışma insan üzerinde yapılan bir çalışma olmayıp ticari olarak satılan biyolojik materyal üzerinde yapılan bir çalışma olduğu için Etik Kurul Onay Belgesi gerekmez.

Materyaller: $\mathrm{Bu}$ in vitro çalışmada aynı markaya ait (Glasiosite caps, Voco, Germany) A2, A3, A3,5, A4, B3 ve C2 renk kompomerler kullanıldı (Resim 1).

Yöntemler: Çalışmada kullanılan tüm örnekler polivinil klorürden hazırlanmış çapı $8 \mathrm{~mm}$ ve yüksekliği $2 \mathrm{~mm}$ olan içerisinde silindirik yuva bulunan yapışmaz özellikli bir kalıp kullanılarak üretici talimatlarına göre hazırlandı. Bir siman camının üzerine şeffaf strip bant yerleştirildi ve kalıp şeffaf bant üzerine yerleştirildi. Kalıp içerisindeki yuvaya kompomer tabancası ile kompomer uygulandı, ağız spatülü yardımıyla taşan kısımlar düzeltildi. Üzerine şeffaf bant ve başka bir siman camı yerleştirilerek hafif bası uygulandı. Daha sonra örnekler polimerize edilmeden dijital bir radyometrenin (SDI, Australia) okuyucusu üzerine nakledildi. (Resim 2) Optomed 
firması (Optomed, Ölçüm Kalibrasyon Elkt. Tıbbi Sist. San. ve Tic. Ltd. Şti, İstanbul) tarafından kalibrasyonu yapılan (TS EN ISO 60601-1-1), elektrikli, $1000 \mathrm{~mW} / \mathrm{cm} 2$ 1ş1k gücü şiddetine sahip LED bir 1şık cihazı (Woodpecker Led G, China) yardımıyla 20 saniye polimerizasyon gerçekleştirildi.

Polimerizasyon işlemi için 1 şı cihazı örneğe dik gelecek şekilde tutuldu. Işık cihazından gelen 1şı̆̆ın çevreye saçılmaması, direkt örneğe gelmesi ve örneğin gün 1şı̆̆ına maruz kalmaması amacıyla 1şık cihazının ucuna siyah lastik bir halka uyguland. Polimerizasyon sırasında bir akıllı saate ait dijital kronometre (Apple inc. USA) kullanılarak ölçümlerin 1., 5., 10., 15., ve 20. saniyelerinde örnekten geçen direkt 1şık şiddeti değerleri dijital radyometrenin göstergesi izlenerek kaydedildi. Ayrıca kullanılan 1şık cihazının her 5 saniyede bir ses çıkararak uyarı vermesi de ölçümlerin kaydedilmesinde dikkate alındı. Ölçümler $21 \pm 2 \mathrm{C}^{\mathrm{o}}$ oda sıcaklığında yapıldı.

Istatistiksel Analiz: Verilerin normallik varsayım Shapiro Wilk testi ile incelendi ve verilerin normal dağıldığı belirlendi ( $p>0,05)$. Varyans homojenlik testleri Levene testi ile incelenmiş ve varyansların homojen olduğu bulunmuştur. Bu nedenlerle verilerin analizinde tek yönlü varyans analizi kullanılmıştır. Gruplar arası farklılıkların belirlenmesinde Duncan çoklu karşılaştırma testinden yararlanılmıştır. Verilerin analizinde Ondokuz Mayıs Üniversitesi lisanslı SPSS paket programı kullanılmıştır. Tanımlayıcı istatistikler ortalama \pm std hata şeklindedir.

\section{BULGULAR}

Aynı markaya ait A2, A3, A3,5, A4, B3 ve C2 renk kompomerler kullanilarak yapilan ve kompomerlerin direkt 1 şı geçirgenliğinin analiz edildiği bu çalışmada grup içi ve gruplar arası karş1laştırmalarda istatistiksel olarak anlamlı sonuçlar elde edildi. Sonuçlar Tablo 1'de gösterilmektedir. Tabloya göre en az direkt 1şık geçirgenlik değeri C2 renk kompomerlerde birinci saniyede, en fazla direkt 1şık geçirgenlik değeri A2 renk kompomerlerde 20 . saniyede gözlendi.

Grup içi karşılaştırmalarda her renk tonu tek tek incelendiğinde; A2 renk kompomerlerin 1. saniyedeki direkt 1şık geçirgenlik değerinin daha sonraki ölçüm değerlerinden düşük olduğu $(p=0,003)$, diğer ölçüm zamanlarındaki direkt 1şı geçirgenlik değerlerinin ise benzer olduğu, en yüksek direkt 1şık geçirgenlik değerinin 20. saniyedeki ölçümde gözlendiği anlaşıldı. $\mathrm{Bu}$ durum $\mathrm{A}$ grubu diğer kompomerlerde benzer şekildedir $(p<0,001)$. Sadece A3,5 renk kompomer grubunda 15 . ve 20 . saniye verileri birbirine eşit olarak bulundu. C2 renk kompomerlerde en düşük ölçüm değeri 1. saniyede en yüksek 20. saniyede gözlendi. Ancak A grubu kompomerlerden farklı olarak $\mathrm{C} 2$ renk kompomerlerde 1 . ve 5. saniye ölçümleri arasında ve sonraki ölçüm zamanları ile 1. ve 5. saniye ölçüm değerleri arasında istatistiksel olarak anlamlı farklıliklar bulundu $(\mathrm{p}<0,001)$. C2 renk gurubu 10. saniyeden sonra benzer 1şık geçirgenlik değerleri gösterdi. C2 renk için geçerli bu durum B3 renk için de geçerlidir.

Gruplar arası karşılaştırmalarda, A2, A3 ve B3 renk gruplarından elde edilen direkt 1 şı $1 \mathrm{k}$ geçirgenliği değerleri birbirine benzer, A3,5, A4 ve C2 renk kompomerlerden ise daha yüksek olduğu bulundu.

\section{TARTIŞMA VE SONUÇ}

Ağı sağlığı kadar estetiğin de ön plana çıktığı, estetiğin neredeyse fonksiyonun önüne geçtiği günümüzde, estetik dolgu maddeleri ile ilgili yapılan araştırma sayısı gün geçtikçe artmaktadır. ${ }^{13}$ Bu çalışma, kompomer renginin direkt ışık geçirgenliği üzerine etkisi incelemek amacıyla planlanıp, aynı marka, aynı kalınlıkta hazırlanan örnekler, aynı 1şık cihazı, aynı hazırlama ortamı ve farklı renk kompomerler kullanılarak gerçekleştirilerek, kompomer örneklerin direkt 1 şı geçirgenliğinin kompomer renginden etkilendiği sonucuna ulaşıldı. Kompomerlerde ana yapıyı oluşturan BISGMA ve UDMA yüksek moleküler ağırlık iken, TEGDMA düşük moleküler ağırlıktır ve diğer monomerlerden daha hızlı çözünür. ${ }^{2}$ Farklı monomerler içeren rezin materyallerin 1 şı geçirgenliklerinin de farklı olması bu sebebe dayandırılabilir. Fakat bu çalışmada yalnızca farklı renk tonlarının, direkt ışık geçirgenliğine etkisini incelemek amaçlandığı için yukarıda zikredilen durumu elimine etmek amacı ile tek bir üreticiye ait farklı renkte kompomerler tercih edildi. ${ }^{14,15}$

Çalışmada kullanılan kompomerlerin üretici firması, kompomer örneklerin 4-23 $\mathrm{C}^{\text {or }}$ de saklanmasını tavsiye ettiği için bu çalışma da $21 \pm 2 \mathrm{C}^{\text {o }}$ oda isısında yapıld1. Üretici firma kompomerlerle birlikte şeffaf striplerin kullanılabileceğini, 1şık cihazının restorasyon yüzeyine yakın olması gerektiğini, $5 \mathrm{~mm}$ den fazla olan mesafelerde polimerizasyon sorunları, renkleşme ve pulpitis benzeri şikayetlerin olabileceğini bildirmiştir. ${ }^{16} \mathrm{Bu}$ çalışmada da 1şık cihazının ucu örneklerle temasta olacak şekilde ve dik bir açıyla uyguland.

Önceki çalışmalarda rezin örneklerin silindir şeklinde çeşitli kalınlıklarda hazırlandığı görülmüştür. 2 mm'den daha kalın yapılan uygulamalar sonucunda 
polimerizasyonun yetersiz kaldığı bildirilmiştir. ${ }^{17}$ Fakat kompozit rezinin türüne göre $1 \mathrm{~mm}$ ile $6 \mathrm{~mm}$ arasında örnek hazırlayan çalışmalar mevcuttur. ${ }^{11,18}$ Bu çalışmada maksimum polimerizasyon sağlamak için Yap ve ark. ${ }^{19}$ ve Mohamed-Tahir ve ark.'nın ${ }^{17}$ çalışmalarında olduğu gibi $2 \mathrm{~mm}$ kalınlığında silindir şeklinde örnekler hazırlandı. Yapılan birçok çalışmada polimerize edilen kompozit rezin örneklerinin alt yüzeyine ulaşan 1şık şiddetinin azaldığı gösterilmiştir. ${ }^{20,21} \mathrm{Bu}$ çalışmada da radyometre ile yapılan ölçümlerde $1000 \mathrm{~mW} / \mathrm{cm}^{2}$ çıkışlı 1şık şiddetinin materyalden geçtiğinde önemli ölçüde azaldığı görüldü. Kompozit materyallerin polimerizasyonunda hekimin göz önünde bulundurması gereken önemli noktalardan biri de 1şı̆̆ın kompozitin derin noktalarına penetrasyonunun sağlanmasıdır. Hem adeziv sistemin, hem de rezin materyalinin uzun süreli klinik başarısı için etkili bir polimerizasyonun gerekli olduğu bilinmektedir. ${ }^{14}$ Yeterli polimerizasyonun sağlanması açısından rezinlerin 1şık geçirgenlik değerlerinin bilinmesi oldukça önemlidir. ${ }^{22}$ Rezin materyallerin yetersiz polimerizasyonunda birçok faktör rol oynamaktadır. Bu faktörler arasında; restoratif materyalin rengi, 1şık kaynağı ucu ve rezin materyal arası mesafenin uzak olması, yetersiz süre 1şık uygulaması, 1şı ğın yoğunluğunun az olması bulunmaktadir. $^{23}$

Rezin içerikli materyallerde polimerizasyonun sağlanabilmesi için geleneksel halojen 1şık cihazları, yüksek enerji yoğunluklu (turbo tip) halojen 1 şık cihazları, UV 1şık cihazları, plazma ark ışık üniteleri, lazer polimerizasyon üniteleri ve 1şık yayan diyotlar (LED) gibi farklı türde 1şık cihazları kullanılabilir. LED 1ş1k cihazları yüksek 1şık gücü yoğunluğuna sahip olması, kısa ekspoz süreleri ile uygulanması, darbelere ve vibrasyona dirençli ve taşınabilir olması ve diğer cihazlara göre daha az 1sı üretmesi gibi avantajlara sahiptir. ${ }^{5}$ Işık kaynaklarının rezin esaslı materyallerin polimerizasyonu üzerine etkisi incelendiğinde 1şınlama süresinin ve 1şık cihazının materyal yüzeyine mesafesinin etkili olduğu görülmüştür. ${ }^{24} \mathrm{Bu}$ çalışmada ise 1 şı cihazlarından kaynaklı farklılıkların ışık geçirgenlik değerleri üzerine etkisi istenmediği için her örnekte sabit süre ve mesafede aynı LED 1şık kaynağı kullanıldı.

Yeterli polimerizasyon için daha önce LED 1şık cihazlarında 40 sn işınlama önerilse de, yeni nesil $1000 \mathrm{~mW} / \mathrm{cm}^{2}$ 1şı gücü şiddetine sahip LED ler için 20 sn 1şınlama süresinin yeterli olduğu belirtilmektedir. Bununla birlikte yüksek enerji çıkışının yüksek 1S1 üretimi gibi bir dezavantaj1 da söz konusudur. ${ }^{25}$ Schattenberg ve ark. ${ }^{26}$ yaptıkları çalışmada 5 ila 20 sn arasında 1şınlama sürelerini kullanarak mümkün olan en kısa sürede polimerizasyonu sağlamaya çalışmışlardır. Toplamda 20 sn işınlama yapılan bu çalışmada da, 1şınlamanın 1., 5., 10., 15., ve 20. saniyelerinde materyalden geçen 1 şı şiddeti yoğunluğu ölçülerek 1şınlama süresinin 1şık geçirgenliği üzerinde bir etkisi olup olmadığı da araştırıldı. Estetik restoratif bir materyal olan kompomerlerin polimerizasyonunun başlaması için kullanılan sarı renkli kamforokinon, 450-470 nm dalga boyuna sahip mavi ışığa duyarlıdır. Uygun dalga boyunda yeterli süre polimerize edilen kompomerlerin içerisindeki kamforokinon sarı rengini kaybeder ve renksiz hale gelir. ${ }^{3}$ Aynı markaya ait farklı renkteki kompomerlerin 1şık geçirgenlik değerlerinin karş1laştırıldığı bu çalışmada, başlangıçtan 20. saniyeye kadar örneklerin ışı geçirgenliğinin artmasının sarı renkli fotobaşlatıcıların zamanla renksiz hale gelmesiyle ilgili olabileceği düşünüldü. Elde edilen sonuçlarda 1şı geçirgenliğinin ilk saniyelerde hızla arttığı fakat 10. saniyeden sonra benzer seyrettiği görüldü. Polimerizasyonun başlaması ile momomer halden polimer hale dönüşüm de 1şık geçirgenliğinin zamanla artmasına ve dönüşüm devam edip monomer miktarı azaldıkça geçirgenlik değerlerinin birbirine yakın seyretmesine bir neden olarak gösterilebilir. ${ }^{7}$ Optimum polimerizasyon için materyal içerisinden geçerek karşı tarafa ulaşan 1 şı miktarı kesin olarak belirtilmese de, bu çalışma için farklı renkler arasında yapılan karşılaştırmada özellikle A2 ve C2 renk kompomerler arasında polimerizasyon dereceleri arasında fark olduğu da düşünülebilir.

Leloup ve ark. ${ }^{10}$ koyu renkli estetik materyallerin opak olanlara göre daha az 1ş1k geçirgenliği olduğunu belirtmektedirler. Koyu tonlardaki rezinlerin 1şığı absorbe ederek, açık tonlara göre daha zor polimerize oldukları bildirilmiştir. Bu durum çalışmanın sonuçları ile uyumludur.

Dental terimlerde renk tonu, yaygın olarak kullanılan VITA klasik renk skalasında A, B, C veya D harfleriyle temsil edilir. ${ }^{27} \mathrm{~A}$ renginin beş alt tonu vardır. $\mathrm{B}, \mathrm{C}$ ve $\mathrm{D}$ renkleri dört alt tona ayrilır. Renklerin yoğunluğu ise chroma olarak adlandırılır. Chroma VITA skalasında rakamlar ile ifade edilir. Farklı renklerdeki kompozit rezinlerin polimerizasyon derinliğinin değerlendirildiği bazı çalışmalarda, koyu renkteki kompozit rezinlerin polimerizasyon derinliğinin açık renkteki kompozit rezinlere oranla daha az olduğu, bunun sebebinin kompozit rezinlere renk vermek amacı ile katılan renklendirici maddelerden kaynaklanabileceği bildirilmiştir. $^{6}$ 
Bala ve ark. ${ }^{28} \mathrm{~A} 1, \mathrm{~A} 2$, A3 ve B3 kompozit kullanarak en yüksek polimerizasyon derinliğinin A1 renginde, en düşük değerlerin ise B3 ile elde edildiğini bildirmiştir. Marka sabit tutularak renk farklılıklarının etkisinin ortaya konulması amaçlanan bu çalışmada ise daha koyu olan C2 renk kompomer açık renkli kompomerlerden daha düşük 1şık geçirgenlik değeri, A2, A3 ve B3 renk kompomerler ise benzer direkt 1şık geçirgenlik değerleri gösterdi.

Kompozit rezinlerin translüsensi özelliği estetiğin yanı sıra direkt 1şık geçirgenliği ve polimerizasyon derecesi ile doğrudan ilgilidir. Yu ve Lee ${ }^{29}$ kompozit rezinlerde translüsensi üzerine yaptıkları çalışmada rezinin chroma değeri ile translüsensi özelliği arasında negatif bir korelasyon olduğunu belirtmişlerdir. Çalışmada A2, A3 ve B3 renkte kompomerlerin 1şı geçirgenliklerinin benzer olmasının sebebi yakın chroma değerlerine sahip olmaları olabilir.

VITA skalası dikkate alındığında C renk grubu içerisinde gri tonları ağırlık kazanmaktadır. Kompozit rezinlerde renk, farklı pigmentlerin karıştırılması ile elde edilir. Tüm renklerin karışımı siyahtır. Gri gibi siyaha yakın bir renk tonunu elde etmek için diğer renklere göre daha fazla pigment eklenmesi gerekmektedir. $^{30} \mathrm{Bu}$ durumun $\mathrm{C}$ grubunda direkt 1 şı geçirgenlik değerlerinin daha az olmasına neden olabileceği düşünüldü.

Sonuç olarak; aynı markaya ait farklı renkte kompomer rezinlerin direkt 1 şı geçirgenliklerinin değerlendirildiği bu çalışmada, eşit koşullarda polimerizasyon gerçekleştirilse bile 20. saniyedeki 1şık geçirgenlik değerlerinin birbirinden farklı olduğu ve kompomer rezinlerde kullanılan renk pigmentlerinin direkt 1şık iletim değerlerini etkilemekte olduğu görüldü. Hekimler estetiğin yanı sıra bu durumu da dikkate alarak materyal seçimi yapmalıdır. Koyu renkte materyal kullanıldığında yeterli derecede polimerizasyonu sağlayabilmek adın materyal kalınlığı ve 1şınlama süresi gibi parametrelere özen gösterilmesi gereklidir.

Etik Komite Onayı: Bu çalışma insan üzerinde yapılan bir çalışma olmayıp ticari olarak satılan biyolojik materyal üzerinde yapılan bir çalışma olduğu için Etik Kurul Onay Belgesi gerekmez.

Çıkar Çatışması: Yazarlar çıkar çatışması bildirmemektedir.

Yazar Katkıları: Fikir - BÖ; Denetleme - BÖ; Malzemeler - BÖ, ZK, HZBG; Veri toplanması ve/veya işlemesi - BÖ, ZK, HZBG; Analiz ve/ veya yorum BÖ, ZK, HZBG; Yazıyı yazan - BÖ, ZK.
Hakem değerlendirmesi: Dı̧̧ bağımsız.

Teşekkür: Ölçümlerde kullanılan radyometre cihazı temini için Arı Dental'e teşekkür ederiz.

\section{KAYNAKLAR}

1. Pummer A, Cieplik F, Nikolic M, Buchalla W, Hiller KA, Schmalz G. Longevity of posterior composite and compomer restorations in children placed under different types of anesthesia: a retrospective 5-year study. Clin Oral Investig. 2020;24(1):141-150. doi:10.1007/s00784-01902911-2

2. Ertürk Avunduk AT, Aksu S, Delikan E. The effects of mouthwashes on the color stability of resin-based restorative materials. International Journal of Dental Science. 2020;23-1:91-102. doi:10.15517/IJDS.2020.43004

3. Janda R, Roulet JF, Latta M, Steffin G, Rüttermann S. Color stability of resin-based filling materials after aging when cured with plasma or halogen light. Eur J Oral Sci. 2005;113(3):251257. doi:10.1111/j.1600-0722.2005.00217.x

4. Tokay U, Koyutürk AE, Aksoy A, Özmen B. Do the monomers release from the composite resins after artificial aging. Microsc Res Tech. 2015;78 (4):255-259. doi:10.1002/jemt.22468

5. Drost T, Reimann S, Frentzen M, Meister J. Effectiveness of photopolymerization in composite resins using a novel 445-nm diode laser in comparison to LED and halogen bulb technology. Lasers Med Sci. 2019;34(4):729-736. doi:10.1007/s10103-018-2651-1

6. Kawaguchi M, Fukushima T, Miyazaki K. The relationship between cure depth and transmission coefficient of visible-light-activated resin composites. J Dent Res. 1994;73(2):516-521. doi:10.1177/00220345940730020601

7. Hyun HK, Christoferson CK, Pfeifer CS, Felix C, Ferracane JL. Effect of shade, opacity and layer thickness on light transmission through a nano-hybrid dental composite during curing. J Esthet Restor Dent. 2017;29(5):362-367. doi:10.1111/jerd.12311

8. Tsai PC, Meyers IA, Walsh LJ. Depth of cure and surface microhardness of composite resin cured with blue LED curing lights. Dent Mater. 2004;20(4):364-369. doi:10.1016/S0109-5641 (03)00130-1

9. Duruk G, Kızılcı E, Kılıç MÇ. Rezin kompozitlerin mikrosertliğine kompozit kalınlıkları ve 
1şınlama sürelerinin etkisi. Turkiye Klinikleri J Pediatr Dent-Special Topics. 2015;1(1):37-41.

10. Leloup G, Holvoet PE, Bebelman S, Devaux J. Raman scattering determination of the depth of cure of light-activated composites: influence of different clinically relevant parameters. J Oral Rehabil. 2002;29(6):510-515. doi:10.1046/j.1365 -2842.2002.00889.x

11. Rode KM, de Freitas PM, Lloret PR, Powell LG, Turbino ML. Micro-hardness evaluation of a micro-hybrid composite resin light cured with halogen light, light-emitting diode and argon ion laser. Lasers Med Sci. 2009;24(1):87-92. doi:10. 1007/s10103-007-0527-x

12. Koupis NS, Vercruysse CW, Marks LA, Martens LC, Verbeeck RM. Curing depth of (polyacidmodified) composite resins determined by scraping and a penetrometer. Dent Mater. 2004;20 (10):908-914. doi:10.1016/j.dental.2004.01.001

13. Bezgin T, Ozer L, Tulga Oz F, Ozkan P. Effect of toothbrushing on color changes of esthetic restorative materials. J Esthet Restor Dent. 2015;27 Suppl 1:S65-73. doi:10.1111/jerd.12136

14. Aguiar FH, Lazzari CR, Lima DA, Ambrosano GM, Lovadino JR. Effect of light curing tip distance and resin shade on microhardness of a hybrid resin composite. Braz Oral Res. 2005;19(4):302-306. doi:10.1590/s180683242005000400012

15. Balbinot E, Pereira M, Skupien JA, Balbinot CEA, da Rocha G, Vieira S. Analysis of transmittance and degree of conversion of composite resins. Microsc Res Tech. 2019;82(11):19531961. doi:10.1002/jemt.23364

16. Voco Dental. Glassiosite kullanım talimatı https://www.voco.dental/tr/portaldata/1/ resources/products/instructions-for-use/tr/ glasiosite_ifu_tr.pdf. Erişim tarihi 25 Kasım 2020.

17. Mohamed-Tahir MA, Tan HY, Woo AA, Yap AU. Effects of $\mathrm{pH}$ on the microhardness of resinbased restorative materials. Oper Dent. 2005;30 (5):661-666.

18. Tabassum S, Hameed MH, Khan FR. Comparison of the depth of cure of flowable composites polymerized at variable increment thicknesses and voltages: an in vitro study. Contemp Clin Dent. 2019;10(2):220-225. doi:10.4103/ ccd.ccd_635_18
19. Yap AU. Effectiveness of polymerization in composite restoratives claiming bulk placement: impact of cavity depth and exposure time. Oper Dent. 2000;25(2):113-120.

20. Ilie N, Bucuta S, Draenert M. Bulk-fill resinbased composites: an in vitro assessment of their mechanical performance. Oper Dent. 2013;38 (6):618-625. doi:10.2341/12-395-L

21. Ilie N, Stark K. Curing behaviour of highviscosity bulk-fill composites. J Dent. 2014;42 (8):977-985. doi:10.1016/j.jdent.2014.05.012

22. Yamanel K, Baltacıoğlu İ, Bağış HY. Opak renkli kompozit rezinin 1şık geçirgenliğine etkisi. AÜ Diş Hek Fak Derg. 2009;36(3):131-135.

23. Ağaccioğlu M, Aytaç F. Kompozit rezinlerin polimerizasyon özellikleriyle ilgili analiz yöntemleri. Turkiye Klinikleri J Dental Sci. 2019;25(2):201-212. doi:10.5336/dentalsci.201758555

24. Knobloch L, Kerby RE, Clelland N, Lee J. Hardness and degree of conversion of posterior packable composites. Oper Dent. 2004;29(6):642 -649 .

25. Bektaş ÖÖ, Siso ŞH, Eren D. Işık Kaynakları, Polimerizasyon ve Klinik Uygulamalar EÜ Dişhek Fak Derg. 2006;27:117-124.

26. Schattenberg A, Lichtenberg D, Stender E, Willershausen B, Ernst CP. Minimal exposure time of different LED-curing devices. Dent Mater. 2008;24(8):1043-1049. doi:10.1016/ j.dental.2007.12.001

27. Fondriest J. Shade matching in restorative dentistry: the science and strategies. Int J Periodontics Restorative Dent. 2003;23(5):467-479.

28. Bala O, Üçtaşlı MB, Arısu HD. Kompozit rezinlerin polimerizasyon derinliği üzerine farklı polimerizasyon teknikleri ve rengin etkileri. GÜ Diş Hek Fak Derg. 2008;25(3):7-14.

29. Yu B, Lee YK. Influence of color parameters of resin composites on their translucency. Dent Mater. 2008;24(9):1236-1242. doi:10.1016/ j.dental.2008.01.016

30. Tokuyama Omnichroma Teknik Rapor https:// www.tokuyamaturkiye.com/upload/teknik/ omnichroma.pdf. Erişim tarihi 25 Kasım 2020. 


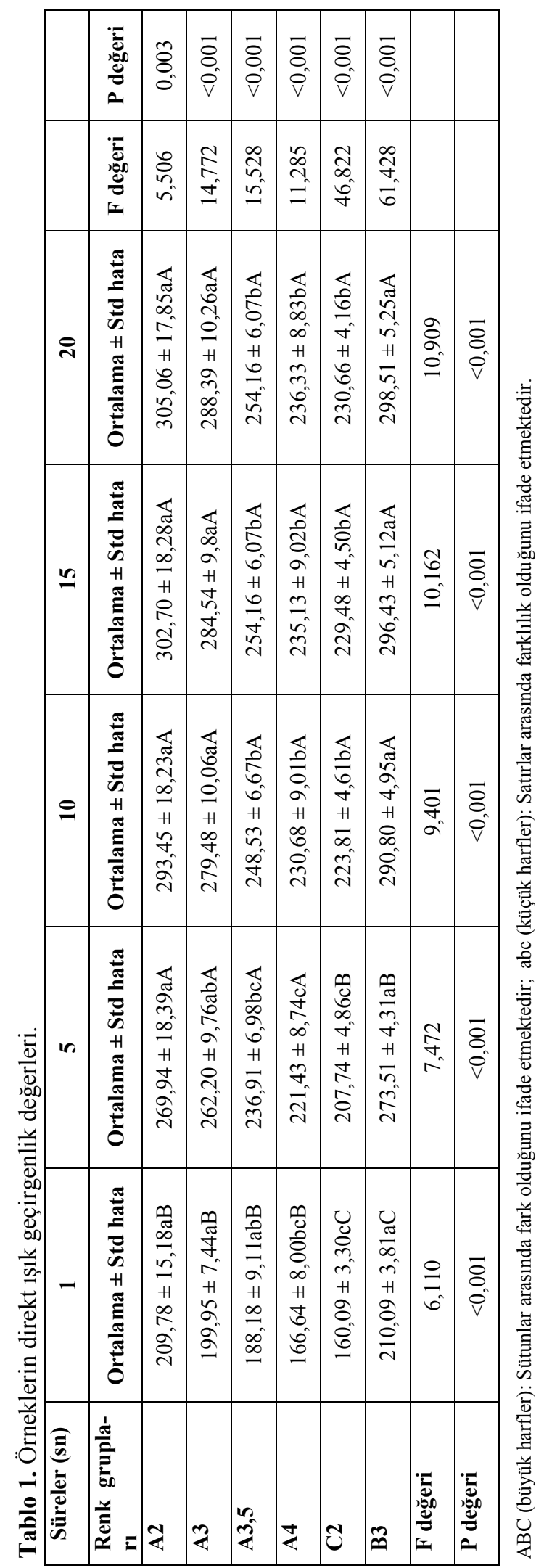




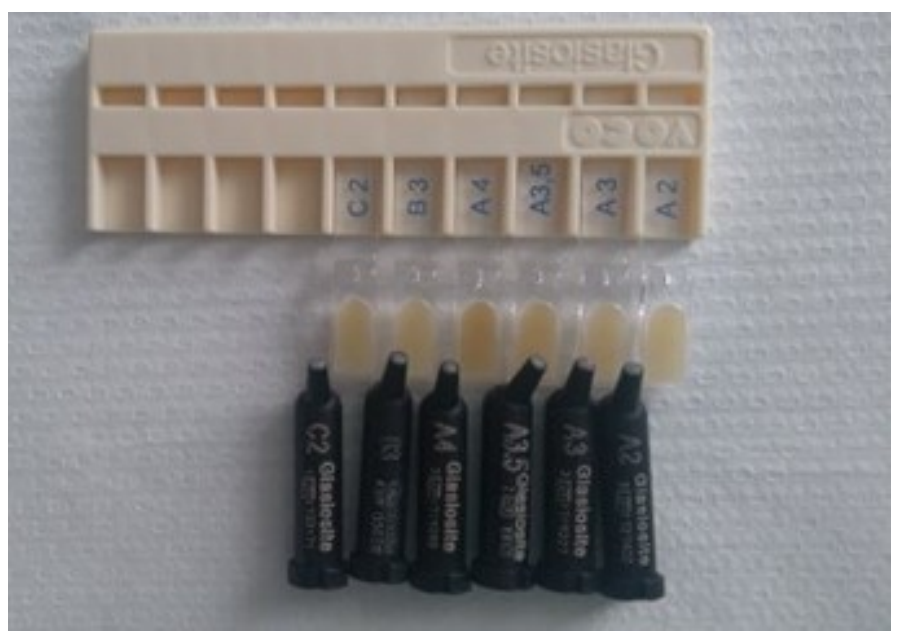

Resim 1. Çalışmada kullanılan kompomer rezinlerin renk skalası. 


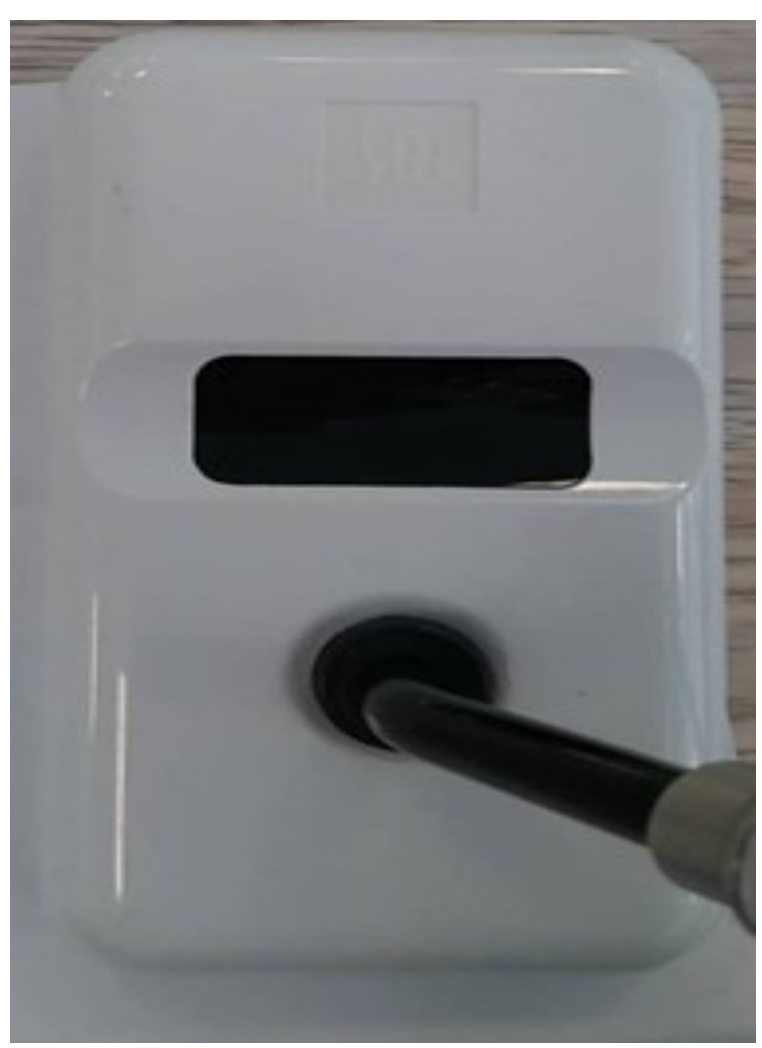

Resim 2. Çalışmada kullanılan radyometre cihazı. 